\title{
A descriptive analysis of TB patients registered for treatment using the Web based Case based Portal (NIKSHAY ), in the district Byculla of Mumbai, India
}

\author{
Article by Syed Imran Farooq Irshad $\mathrm{Ali}^{1}$, Dr Jayashree Shinde ${ }^{2}$,Dr Minni Khetarpal ${ }^{3}$, \\ Dr Manohar H Pawar ${ }^{4}$ \\ ${ }^{1}$ Technical Support Network-WHO Country Office for India \\ ${ }^{2}$ District TBOfficer - Byculla, Municipal Corporation of Greater Mumbai \\ ${ }^{3}$ City TBOfficer-Mumbai, Municipal Corporation of Greater Mumbai \\ ${ }^{4}$ State TBOfficer-Pune, Public Health Department, Maharashtra \\ Email:simfarooq@gmail.com
}

\begin{abstract}
Objectives: To describe the major characteristics of Revised National TB Control Programme notified TB cases in district Byculla, Mumbai from January 2013 through December 2013

Design: Descriptive analysis of 1024 reported TB cases extracted from the Web based case based portal of RNTCP-NIKSHAY

Setting: Twenty, Primary, secondary and tertiary health care centres across the district of Byculla, Mumbai

Population: A multivariate population of TB patients of all ages and gender with confirmed TB registered in NIKSHAY by the district of Byculla, Mumbai from January 2013 to December 2013

Main outcome measure: Microbiologically or clinically conformed TB case registered

Results

The Total TB case notification rate was found to be 213 per 1,00,000 population in the year 2013.The highest proportion, 24.8\% $(p<0.000)$ of TB cases were notified in the age group 15-24 although the peak (22.5\%) for females was observed in the age group 25-34 years. Extra pulmonary TB was calculated to be $34 \%(p<0.000)$ but was disproportionately high $(48 \%)$ in the females. $31 \%(p, 0.000)$ of the patients sputum result was "NA"
\end{abstract}

\section{Acronyms}

$\begin{array}{ll}\text { STO } & \text { State TB Officer } \\ \text { DEO } & \text { Data Entry Operator } \\ \text { TBHV } & \text { Tuberculosis Health Visitor } \\ \text { DOT } & \text { Directly Observed Treatment } \\ \text { PHI } & \text { Peripheral Health Institute } \\ \text { RNTCP } & \text { Revised National TB Control Programme } \\ \text { CTD } & \text { Central TB Division } \\ \text { NIC } & \text { National Informatics Centre } \\ \text { MCGM } & \text { Municipal Corporation of Greater Mumbai } \\ \text { MLE } & \text { Monitoring, Learning and Evaluation } \\ \text { TU } & \text { TB Unit } \\ \text { DMC } & \text { Designated Microscopy Centre } \\ \text { DR } & \text { TB Drug Resistant TB } \\ \text { DTC } & \text { District TB Centre } \\ \text { DTO } & \text { District TB Officer } \\ \text { ICTCs } & \text { Integrated Counseling and Testing Centres } \\ \text { ART } & \text { Anti-Retroviral Therapy } \\ \text { STD } & \text { Sexually Transmitted Disease } \\ \text { CoE } & \text { Centre of Excellence }\end{array}$


South American Journal of Public Health

Special Edition May 2016

$\begin{array}{ll}\text { NSP } & \text { 2012-17 National Strategic Plan 2012-17 } \\ \text { TN Medical college } & \text { Topiwala Nair Medical College } \\ \text { HBCs } & \text { High Burden Countries } \\ \text { NSP } & \text { New Sputum Smear Positive } \\ \text { NSN } & \text { New Sputum Smear Negative }\end{array}$

\section{Introduction:}

Despite all the advances made in TB control based on the WHO endorsed DOTS strategy ${ }^{1}$, TB continues to be a major public health challenge ${ }^{2}$. WHO estimates 8.6 million people developed TB and 1.3 million died from the disease ${ }^{2}$. The incidence of TB is coming down across all the WHO regions at a slow rate of $\sim 2 \%$ annually which is not sufficient to achieve the MDGs for $\mathrm{TB}^{2}$.

India with $26 \%$ of global TB burden is among the $22 \mathrm{HBCs}$ that account for $81 \%$ of global TB incidence. Estimated TB incidence rate is 176 per lakh population per year. India runs one of the biggest National TB Programme named of Revised National TB Control Programme (RNTCP). Post evaluation of National TB Control Programme (NTP) a revised programme based on WHO recommended DOTS strategy was pilot tested during 1993-97 and implemented across the country in the year 20063.

Since 2007, country has been successfully achieving the global DOTS targets of $85 \%$ cure rate among NSP and 70\% case detection of such cases ${ }^{4}$. But over the last 5-6 years the case detection has plateaued and has been a concern for RNTCP.

RNTCP has a well-defined organizational structure at National, regional, district and sub district level ${ }^{3}$. The CTD at National Level provides overall technical and operational guidance for implementation of TB control activities in the country. The State TB cell is responsible for Supervision and MLE activities \& programme management at State (Regional) level. The DTC is responsible for the district level activities for TB control, while the unique sub district level, TB Unit is the programme management unit for a block of 1,50,000 to 2,50,000 population. PHI is the unit of implementation for RNTCP, where a Medical officer is responsible for TB diagnostic and treatment activities for a population of 50,000 to 1, 00,000 based on the geographical area ( Tribal, urban, rural or hilly) and access (underserved areas) to the services.

The National TB Control Programme of India-Revised National TB Control Programme launched a web based case based TB notification portal-NIKSHAY in May 2012 to improve TB surveillance from an Epi-Info based aggregated quarterly reporting to a real time web based case based notification system ${ }^{5}$. This system has given an opportunity to look into patient wise details for better understanding the profile of TB patients.

\section{Background:}

Mumbai is the capital city of the state of Maharashtra. It's the most populous city in the country with a population of 12.48 millions. $\sim 60 \%$ of the Mumbai population resides in slums and slums like areas. Mumbai suffers from major urbanization problems seen in many fast growing cities in developing countries: absence of civic amenities coupled with lack of primary healthcare services in most of the non-notified urban poor settlements have an adverse impact on the health status of its residents ${ }^{6}$. Mumbai has a flourishing, unregulated and unevenly distributed private health sector. $>70 \%$ of the population seeks health care from private sector ${ }^{7} .37 \%$ of the population of Mumbai is migratory ${ }^{8}$. The first point of care for the lower and middle class strata is an informal provider ${ }^{9}$. HIV TB co-infection and DR TB adds up to the misery of TB control. For programme management purposes, RNTCP has divided Mumbai into 24 districts, which correspond to the administrative municipal wards of Mumbai.

\section{Methods}

\section{Study Area}


Byculla (E-Ward) is one of the RNTCP districts of Mumbai. District Byculla is a district with population of 0.48 Million, located in the south of Mumbai city, Maharashtra. The district was chosen as it has good mix of primary secondary and tertiary care institutes in various health posts, dispensaries, Grant Government Medical College \& JJ hospital and TN Medical College. The district has ICTCs in 7/20 PHIs, STD clinic, ART Centre and CoE. There are 3 more major hospitals Prince Aly Khan Hospital, David Sasoon Hospital and Masina Hospital in the district which cater general population and offer TB services also. These hospitals notify the diagnosed \&/or treated TB cases to the DTO, as required by RNTCP.

The RNTCP District Byculla is divided into 2 TB Units, Nawab Tank and Gaurabai Dispensary. There are 10 DMCs and 20 PHIs in the district in toto. The Department of Microbiology of GGMC is the C\&DST laboratory \& JJ Hospital serves as a DR TB services centre for the district.

\section{Data Sources}

The secondary research was performed on the data routinely collected under RNTCP. The data was obtained from the District TB Officer, Byculla through the NIKSHAY platform. Under RNTCP when a patient is initiated on treatment, the PHI opens a treatment card which is made in duplicate. The original treatment card is retained at the PHI and duplicate is kept with the DOT provider. The original treatment card is brought to the DTC by TBHV and entered in NIKSHAY by DEO at DTC. Every DTC is provided with a computer and a DEO by RNTCP. At the district level, data from NIKSHAY platform was exported to MS Excel 2010 software.

\section{Data quality evaluation and descriptive analyses}

Data quality evaluation involved manually checking data associated with each case for completeness and internal consistency. The data cleaning was done in excel. Spelling mistakes in the name of PHI leading to duplication were rectified. Missing values are marked as NA (Not available) for the variables, spures (Sputum result) and HIV status. Population denominator was obtained from the DTO which is the projected population based on Census 2011 adjusted for 2014 considering decadal growth. Data manipulation and statistical analyses were conducted Epidata Analysis V 2.2.2.182. Means and medians were used to describe the data; medians were used when for skewed distributions. Chi2 test were used to determine statistical significance $(\mathrm{p}<0.05)$ for categorical variables.

\section{Results}

The number (percentages) of missing or "NA" values for the eight fields considered in the analysis are shown in table 1

Table 1 TB cases registered in NIKSHAY and associated missing or NA values by field, District Byculla-Mumbai, 2013

\begin{tabular}{|l|l|l|l|l|l|l|l|}
\hline \multicolumn{1}{|c|}{ Type of TB } & \multicolumn{7}{|c|}{ NIKSHAY Entry fields - number (\%) missing values } \\
\hline (n) & PHI & Gender & $\begin{array}{c}\text { Age } \\
\text { Group }\end{array}$ & $\begin{array}{c}\text { Previous } \\
\text { History }\end{array}$ & $\begin{array}{c}\text { Sputum } \\
\text { Result }\end{array}$ & Class & $\begin{array}{c}\text { HIV } \\
\text { Status }\end{array}$ \\
\hline Failure (1 4) & $0(0)$ & $0(0)$ & $0(0)$ & $0(0)$ & $0(0)$ & $0(0)$ & $2(1.1)$ \\
\hline New (71 5) & $0(0)$ & $0(0)$ & $0(0)$ & $0(0)$ & $255(79.9)$ & $0(0)$ & $130(73.4)$ \\
\hline Relapse (1 00) & $0(0)$ & $0(0)$ & $0(0)$ & $0(0)$ & $3(0.9)$ & $0(0)$ & $21(11.9)$ \\
\hline $\begin{array}{l}\text { Retreatment } \\
\text { Others (1 47) }\end{array}$ & $0(0)$ & $0(0)$ & $0(0)$ & $0(0)$ & $56(17.6)$ & $0(0)$ & $18(10.2)$ \\
\hline Transfer In (5) & $0(0)$ & $0(0)$ & $0(0)$ & $0(0)$ & $2(0.6)$ & $0(0)$ & $1(0.6)$ \\
\hline $\begin{array}{l}\text { Treatment after } \\
\text { default (43) }\end{array}$ & $0(0)$ & $0(0)$ & $0(0)$ & $0(0)$ & $3(0.9)$ & $0(0)$ & $5(2.8)$ \\
\hline Total TB cases & $0(0)$ & $0(0)$ & $0(0)$ & $0(0)$ & 319 & $0(0)$ & 177 \\
\hline
\end{tabular}


South American Journal of Public Health

Special Edition May 2016

\begin{tabular}{|l|l|l|l|l|l|l|}
\hline$(1024)$ & & & & & & \\
\hline
\end{tabular}

Among the 1024 TB cases registered, 5 were of type "transfer in" which is a type for patients not diagnosed but received for treatment for other districts, so were dropped from further analysis.

Table 2 Registered TB patients with history of previous treatment and distribution across age group and Type of TB, District Byculla-Mumbai, 2013

\begin{tabular}{|c|c|c|c|c|c|c|}
\hline & \multicolumn{2}{|c|}{ Male } & \multicolumn{2}{|c|}{ Female } & \multicolumn{2}{|l|}{ Total } \\
\hline & No & $\%$ & No & $\%$ & No & $\%$ \\
\hline & \multicolumn{6}{|c|}{ Age Group $(\mathrm{P}<0.000)$} \\
\hline$<=14$ & 23 & 3.6 & 38 & 10.2 & 61 & 6 \\
\hline $15-24$ & 125 & 19.4 & 128 & 34.2 & 253 & 24.8 \\
\hline $25-34$ & 145 & 22.5 & 82 & 21.9 & 227 & 22.3 \\
\hline $35-44$ & 143 & 22.2 & 59 & 15.8 & 202 & 19.8 \\
\hline $45-54$ & 131 & 20.3 & 30 & 8 & 161 & 15.8 \\
\hline $55-64$ & 57 & 8.8 & 22 & 5.9 & 79 & 7.8 \\
\hline \multirow[t]{2}{*}{$>=65$} & 21 & 3.3 & 15 & 4 & 36 & 36 \\
\hline & \multicolumn{6}{|c|}{ TB Classification $(P<\mathbf{0 . 0 0 0})$} \\
\hline Pulmonary & 465 & 72.1 & 203 & 54.3 & 668 & 65.6 \\
\hline \multirow[t]{2}{*}{ Extra Pulmonary } & 180 & 27.9 & 171 & 45.7 & 351 & 34.4 \\
\hline & \multicolumn{6}{|c|}{ History of Previous Treatment $(P>0.29)$} \\
\hline Yes & 196 & 30.4 & 102 & 27.3 & 298 & 29.2 \\
\hline \multirow[t]{2}{*}{ No } & 449 & 69.6 & 272 & 72.7 & 721 & 70.8 \\
\hline & \multicolumn{6}{|c|}{ Type of TB $(P>0.01)$} \\
\hline New & 444 & 68.8 & 271 & 72.5 & 715 & 70.2 \\
\hline Failure & 8 & 1.2 & 6 & 1.6 & 14 & 1.4 \\
\hline Relapse & 73 & 11.3 & 27 & 7.2 & 100 & 9.8 \\
\hline Retreatment Others & 85 & 13.2 & 62 & 16.6 & 147 & 14.4 \\
\hline \multirow[t]{2}{*}{ Treatment after Default } & 35 & 5.4 & 8 & 2.1 & 43 & 4.2 \\
\hline & \multicolumn{6}{|c|}{ HIV Status $(\mathbf{P}>0.3)$} \\
\hline Positive & 68 & 10.5 & 31 & 8.3 & 99 & 9.7 \\
\hline Negative & 472 & 73.2 & 272 & 72.7 & 744 & 73 \\
\hline \multirow[t]{2}{*}{ NA } & 105 & 16.3 & 72 & 19 & 176 & 17.3 \\
\hline & \multicolumn{6}{|c|}{ Sputum Smear Result $(\mathbf{P}<\mathbf{0 . 0 0 0})$} \\
\hline Positive & 306 & 47.4 & 118 & 31.6 & 424 & 41.6 \\
\hline Negative & 174 & 27 & 104 & 27.8 & 278 & 27.3 \\
\hline NA & 165 & 25.6 & 152 & 40.6 & 316 & 31.1 \\
\hline Total TB Cases & 645 & 63.3 & 374 & 36.7 & 1019 & 100 \\
\hline
\end{tabular}

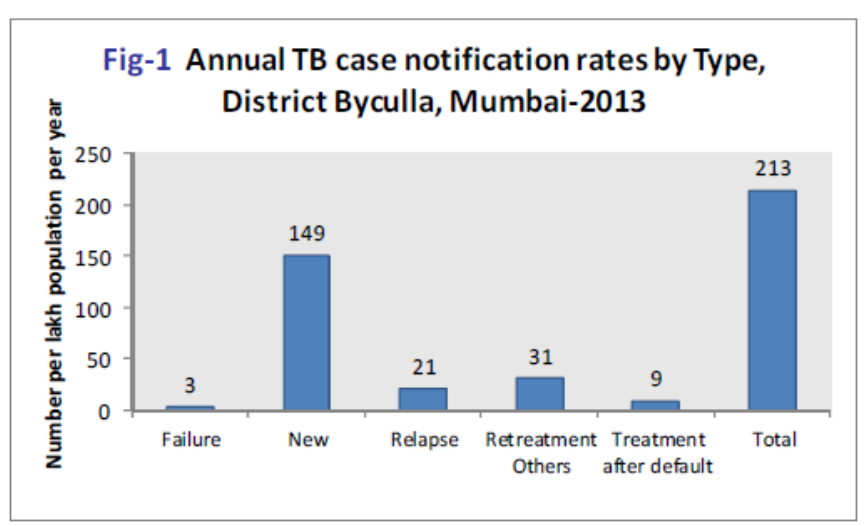


Out of 1019 TB cases, highest number of cases was contributed by JJ Hospital (13.5\%) and Nawab Tank TB Clinic (13.5\%). Highest were New cases were 715 (70.2\%) and retreatment failures- 14(1.4\%) were the lowest. $668(65.6 \%)$ were pulmonary and $430(64.4 \%)$ of them were of type "new".

The reported annual case notification rate of TB was 213 per lakh population per year( Fig 1). Among the new cases $64 \%$ were NSP (Annual case notification rate 57.48 per lakh population per year).The annual case notification rate for NSN TB was 29.26 per lakh population per year.

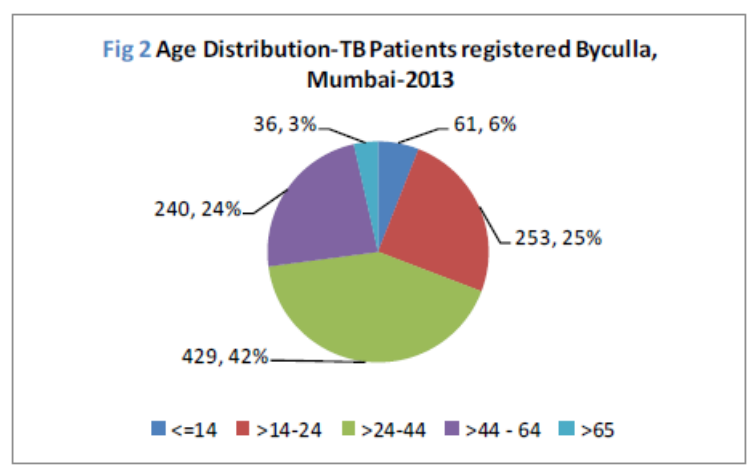

Among the registered TB patients 429 (42\%) were in the age group of $>24-44$ years and the least 36 (3\%) were in the age group of $>65$ years (Fig 2). The highest proportion of TB, $24.8 \%(\mathrm{P}<0.005)$ was found to be in the age group of $15-24$ years with $81 \%$ of the patients in the age group being new TB patients. The proportions remain same across the genders. The mean of ages of TB patients registered was found to be 34.34 years (95\% CI 33.41-35.28) with standard deviation of 15.16. The median was 32 years with an Inter Quartile Range of 22-45 and range of 1-80 year. The median age in males was 36 (IQR 25-48; Range 3-79) whereas in females it was 26 (IQR 20-39; Range 1-80).

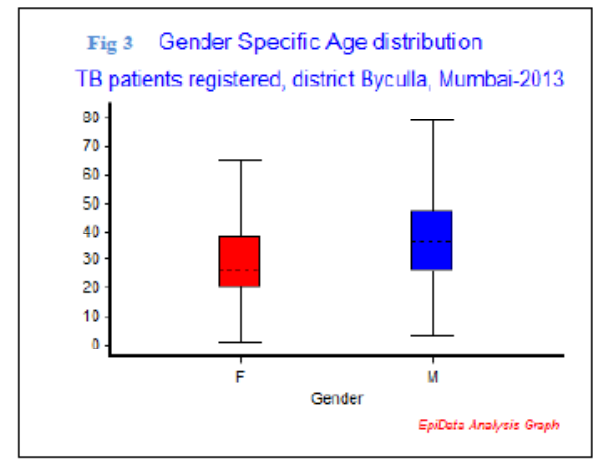

Table 3 Registered TB patients with history of previous treatment and distribution across age group and Type of TB, District Byculla-Mumbai, 2013

\begin{tabular}{|l|l|l|l|l|l|l|}
\hline Type of TB & \multicolumn{2}{|l|}{ Male } & \multicolumn{2}{l|}{ Female } & \multicolumn{2}{l|}{ Total } \\
\hline & No & $\%$ & No & $\%$ & No & $\%$ \\
\hline New & 00 & 0 & 3 & 2.9 & 3 & 1 \\
\hline Failure & 08 & 4.1 & 6 & 5.9 & 14 & 5 \\
\hline Relapse & 72 & 36.7 & 27 & 26.5 & 99 & 33 \\
\hline Retreatment Others & 82 & 41.8 & 58 & 56.9 & 140 & 47 \\
\hline Treatment after default & 34 & 17.3 & 8 & 7.8 & 42 & 14 \\
\hline Age Group & & & & & & \\
\hline$<=14$ & 5 & 2.6 & 9 & 8.8 & 14 & 4.7 \\
\hline $15-24$ & 23 & 11.7 & 25 & 24.5 & 48 & 16.1 \\
\hline $25-34$ & 44 & 22.4 & 27 & 26.5 & 71 & 23.8 \\
\hline
\end{tabular}


South American Journal of Public Health

Special Edition May 2016

\begin{tabular}{|l|l|l|l|l|l|l|}
\hline $35-44$ & 52 & 26.5 & 18 & 17.6 & 70 & 23.5 \\
\hline $45-54$ & 46 & 23.5 & 10 & 9.8 & 56 & 18.8 \\
\hline $55-64$ & 21 & 10.7 & 10 & 9.8 & 31 & 10.4 \\
\hline$>=65$ & 5 & 2.6 & 3 & 2.9 & 8 & 2.7 \\
\hline
\end{tabular}

Among the 1019 TB patients, 298 (29.2\%) gave a history of previous treatment out of which 196 (65.8\%) were male and 52 (26.5\%) belonged to the age group of 25-234 years.

Extra pulmonary TB was found to be $35.7 \%$ among the registered TB patients disproportionately high among females $45.7 \%$ against $27 \%$ in males.

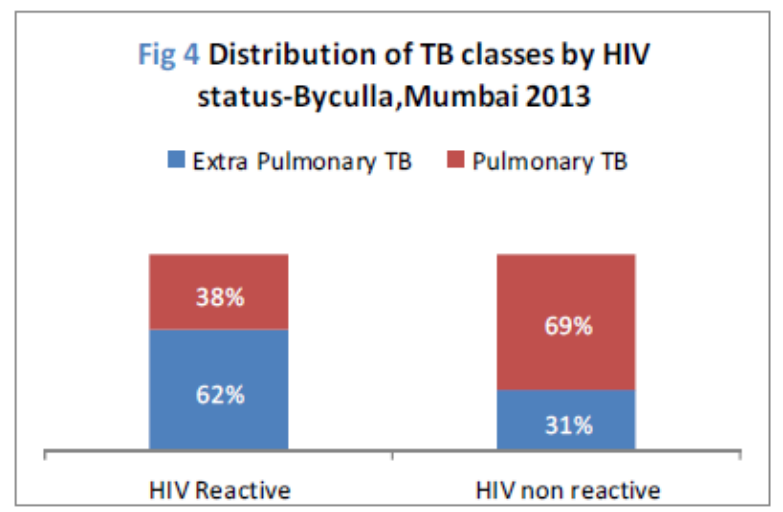

Although less significant ( $\mathrm{P}>0.3$ ), $83 \%$ of the registered TB patients knew their HIV status and $99(9.7 \%)$ of the registered patients were HIV reactive. Among the HIV reactive TB patients $61.6 \%(\mathrm{P}<0.000)$ had extra pulmonary TB whereas among HIV non-reactive the proportion was $31.2 \%$.

\section{Discussions}

The district Byculla in Mumbai has a DMC per 40,000 population which is as per the RNTCP guidelines.6/20 (30\%) PHIs are contributing $>55 \%$ of the total TB patients in the district which includes tertiary care centre, JJ Hospital (138-13.5\%).Contribution of $\mathrm{J} \mathrm{J}$ hospital to the NSP TB cases was $28(10 \%)$ out of 275 registered which is $40 \%$ as compared to $23 \%$ contribution at national level ${ }^{10}$. Among the DMCs, Dr B R Ambedkar Memorial Hospital, Central Railway was the least performing with only 25 TB patients registered in whole year 2013.

The total TB case notification rate of the district 213 per 1,00,000 population is almost double the national notification rate of 113 per 1,00,000 population per year. The higher TB prevalence in the district calls for a better coordination with private sector to decrease the provider delays in diagnosis of $\mathrm{TB}^{11}$. Also the poor risk perception due to lack of awareness contributes to the patients delays.

The female/male ratio was found to be 0.58 and was found to be inversely proportionate to increasing age. The reasons for lower case notification among females are unknown but stigma may be one of the reasons. The role of gender in etiology and disease progression needs further research ${ }^{12}$. The gender specific case notifications are dependent on many socio economic factors such as barriers to access, level of awareness, health seeking behavior ${ }^{13}$, attitude and practices of health care providers. Confidentiality is among the major requirement by female patients while seeking TB care ${ }^{14}{ }^{11}$. The relapses and treatment after default type of TB cases among females registered was found to be $7.2 \%$ and $2.1 \%(\mathrm{P}>0.01)$ respectively. Although insignificant but the conservative Indian society with less interactions and alcohol abuse ${ }^{15}$ among females may have a positive impact on females not getting a relapse episode and completing the first course of anti-TB drugs. $21 \%$ of males and only $2 \%$ of females in India consume alcohol ${ }^{16}$.

In a district with 2 tertiary care units (JJ Hospital and Nair Hospital) the proportion of NSP/NSN TB notified was found to be $>1.9(63 / 34) \mathrm{p}<0.000$. The proportion of NSP/NSN 
cases registered was same in the primary health care facilities and tertiary care facilities. This indicates the poor case finding effort of the institute. Although non-infectious the patients with NSN pulmonary TB progress fast towards infectious disease ${ }^{17}$. This also emphasizes on more sensitive algorithms to be adapted by RNTCP to diagnose NSN at early stage and in immunocompromised patients. The high proportion, 32\% of HIV status "NA" amongst the NSN TB cases calls for higher colocation of HIV TB services which is just 35\% (7/20 PHIs) in the district and frequent shortages of HIV testing kits may lead to low testing ${ }^{18}$.

\section{Conclusions}

The district Byculla in Mumbai has got higher prevalence of TB as compared to national averages. RNTCP needs to increase access to health services, especially females by expanding to services in private and other sectors. It is also recommended that RNTCP takes up measures to increase communication and social mobilization activities in the district. The TBHIV services colocation needs to be increased for better HIV testing among TB patients. Provider initiated testing and counseling may be considered for improved coverage with HIV services. A more sensitive algorithm for diagnosis of smear negative TB, with use of more sensitive and rapid diagnostics to accurately and timely diagnose TB. The skewed proportion of extra pulmonary TB in HIV reactive patients highlights the need of more expertise and resources in public sector for early and precise diagnosis of EPTB.

\section{References}

[1.] Agarwal S, Satyavada A, Kaushik S, Kumar R. Urbanization, Urban Poverty and Health of the Urban Poor: Status, Challenges and the Way Forward. 2007;36(1):121-134.

[2.] Ahsan G, Ahmed J, Singhasivanon P, et al. Gender difference in treatment seeking behaviors of tuberculosis cases in rural communities of Bangladesh. Southeast Asian J Trop Med Public Health. 2004;35(1):126-35. Available at: http://www.ncbi.nlm.nih.gov/pubmed/15272755. Accessed April 15, 2014.

[3.] Bishnu B, Bhaduri S, Kumar AM V, et al. What are the reasons for poor uptake of HIV testing among patients with TB in an Eastern India District? Kranzer K, ed. PLoS One. 2013;8(3):e55229. doi:10.1371/journal.pone.0055229.

[4.] Borgdorff MW, Nagelkerke NJ, Dye C, Nunn P. Gender and tuberculosis: a comparison of prevalence surveys with notification data to explore sex differences in case detection. Int $J$ Tuberc Lung Dis. 2000;4(2):123-32. Available at: http://www.ncbi.nlm.nih.gov/pubmed/10694090.

[5.] Colebunders R, Bastian I. REVIEW ARTICLE A review of the diagnosis and treatment of smearnegative pulmonary tuberculosis. Int J TB Lung Dis. 2000;4(March 1999):97-107. Available at: http://www.ingentaconnect.com/content/iuatld/ijtld/2000/00000004/00000002/art00003?token=005514 cf2d61405847447b496e2f2a314242356b464c4833757e6f4f2858592f3f3b574f07fae6b212220.

[6.] Central TB Division. TB India 2013.pdf. New Delhi; 2013. Available at: http://tbcindia.nic.in/pdfs/TB India 2013.pdf.

[7.] Central TB Division DG of HS. TB India 2011-Annual Status report.; 2011. Available at: http://tbcindia.nic.in/pdfs/RNTCP TB India 2011.pdf.

[8.] Central TB Division DG of HS. 2012 Guidance for TB Notification in India. 2012;(July). Available at: http://tbcindia.nic.in/pdfs/GuidancetoolforTBnotificationinIndia-FINAL.pdf.

[9.] Gautham M, Binnendijk E, Koren R, Dror DM. "First we go to the small doctor": first contact for curative health care sought by rural communities in Andhra Pradesh \& Orissa, India. Indian J Med Res. 2011;134(5):627-38. doi:10.4103/0971-5916.90987.

[10.] Neyrolles O, Quintana-Murci L. Sexual inequality in tuberculosis. PLoS Med. 2009;6(12):e1000199. doi:10.1371/journal.pmed.1000199.

[11.] Programme WGT, - WHORO for S-EA. Tuberculosis control_: the DOTS strategy (Directly Observed Treatment Short-Course)_: an annotated bibliography / compiled by the Global Tuberculosis Programme and the Regional Office for South-East Asia -.1997:WHO/TB/97.228 14 p. Available at: http://apps.who.int/iris/bitstream/10665/63548/1/WHO_TB_97.228.pdf?ua=1. Accessed April 15, 2014. 
South American Journal of Public Health

Special Edition May 2016

[12.] Surendra K. Sharma1,*, Alladi Mohan2,*, L.S. Chauhan3,*, J. P. Narain4,*, P. Kumar5,*, D. Behera6,*, K.S. Sachdeva7,* AK, Programme for TF for I of MC in the RNTC. Contribution of medical colleges to tuberculosis control in India under the Revised National Tuberculosis Control Programme (RNTCP): Lessons learnt \& challenges ahead. Indian J Med Res 137.283-294. Available at: http://icmr.nic.in/ijmr/2013/february/0205.pdf. Accessed April 15, 2014.

[13.] Tamhane A, Ambe G, Vermund SH, Kohler CL, Karande A, Sathiakumar N. Pulmonary tuberculosis in mumbai, India: factors responsible for patient and treatment delays. Int J Prev Med. 2012;3(8):569-80. Available at:

http://www.pubmedcentral.nih.gov/articlerender.fcgi?artid=3429805\&tool=pmcentrez\&rendertype=abs tract.Accessed April 15, 2014.

[14.] Uplekar M, Juvekar S, Morankar S, Rangan S, Nunn P. Tuberculosis patients and practitioners in private clinics in India. Int J Tuberc Lung Dis. 1998;2:324-329.

[15.] Singh D. Migration and occupation in Mumbai: issues and implications. Pap Present 35 th Int Conf ... 2005:1999-2001. Available at: http:/iussp2005.princeton.edu/papers/50938. Accessed April $15,2014$.

[16.] WHO Global TB Report 2013.; 2013.

[17.] World Health Organization. Alcohol in developing societies_: a public health approach . Summary. 2002:1-27. doi:WHO Library Cataloguing-in-Publication Data.

[18.] Prasad R. Alcohol use on the rise in India. Lancet. 2009;373(9657):17-18. doi:10.1016/S01406736(08)61939-X. 